\title{
Anarquistas Negociadores. Una revisión del sentido común historiográfico sobre "el anarquismo argentino" a la luz de algunas experiencias libertarias en el movimiento obrero, Mar del Plata 1940 - 1943
}

\author{
Agustín Nieto* \\ Universidad Nacional \\ de Mar del Plata, Argentina \\ alenieto@mdp.edu.ar
}

Recibido: Julio de 2013

Aprobado: Octubre de 2013

\begin{abstract}
Resumen: En el presente artículo revisaremos algunos rasgos del sentido común historiográfico vigentes en los estudios sobre "el anarquismo" en "Argentina". Estos atributos refieren a la temporalidad del anarquismo, al experimento forista como experiencia anarquista en el movimiento obrero, al eufemismo con el cual se establece la experiencia anarquista en la ciudad de Buenos Aires como "lo nacional", a la dinámica que dicha corriente le imprimó a los conflictos obreros en los cuales tuvo un papel dirigente, resumidos en la frase "todo o nada", a la relación entre anarquismo y Estado, y finalmente a la identificación cuasi mecánica entre esta ideología "arcaica", una organización por oficio y un proceso de trabajo artesanal. Esta labor revisionista será desarrollada a la luz de las acciones de lucha,
\end{abstract}

* Egresado de la Universidad Nacional de Mar del Plata (Argentina), Becario Doctoral del Consejo Nacional de Investigaciones Científicas y Técnicas (CONICET), integrante del Grupo de Estudios Sociales Marítimos (GESMAR). También es miembro de la Red de estudios sobre anarquismo, del colectivo Nuevo Topo y de la Revista de Estudios Marítimos y Sociales. Desarrolla su actividad docente en la cátedra "Estructura y Cambio Social" de la carrera de Sociología en la Facultad de Humanidades de la UNMDP.

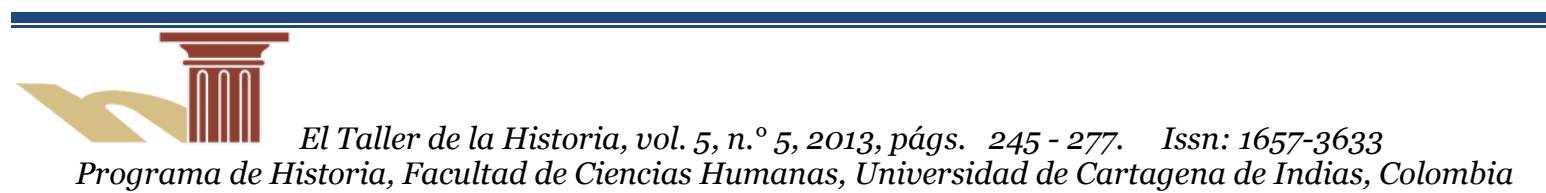


negociación y organización experimentadas por un conjunto heterogéneo de obreros/as de distintos gremios que tuvieron como denominador común encontrarse nucleados y dirigidos por grupos anarquistas de las Juventudes Libertarias y de la Federación AnarcoComunista Argentina, en un territorio singular, Mar del Plata, durante un período particular, los primeros años de la década de 1940.

Palabras clave: sentido común historiográfico, anarquismo, movimiento obrero, Mar del Plata.

\section{Negotiators anarchists. A review of the historiogra- phical common sense of "the Argentine anarchism" in light of some experiences in the libertarian, Mar del Plata 1940 - 1943 labor movement}

Abstract: In this article we will revise some aspects of the historiographic common sense still current in the studies of anarchism in Argentina. These aspects refer to the temporality of anarchism, to the FORA experiment as an anarchist experiment in the labor movement, to the euphemism that establishes the anarchist experience in the city of Buenos Aires as national, to the dynamics that this current gave to the labor conflicts in which it had a leading role (summarized by the phrase "all or nothing"), to the relationship between anarchism and State, and finally to the almost mechanic identification of this archaic ideology with a trade union and a process of craftwork. This revision will be developed through the struggle fight, negotiation and organization of a heterogeneous group of workers from different unions who were all gathered and led by the "Juventudes Libertarias" and the "Federación Anarco-Comunista", both anarchist movements in a singular territory, Mar del Plata, during a particular period, the beginnings of the 1940's.

Key words: historiographic common sense, anarchism, labor movement, Mar del Plata 


\section{Algunas palabras preliminares}

$\mathrm{E}$

n este artículo nos proponemos revisar algunos de los rasgos del sentido común historiográfico (En adelante $\mathrm{SCH}$ ) presentes en los estudios sobre "el anarquismo argentino". ${ }^{1}$ Adelantaremos a continuación al lector un esquema de las características que pensamos constituyentes del sch, que serán abordadas con mayor detalle en el primer apartado. Uno de los rasgos refiere a la temporalidad del anarquismo. Según la visión historiográfica dominante, la experiencia anarquista en el movimiento obrero se limitó a los años que transcurrieron entre finales del siglo XIX y principios del XX, siendo la década de 1910 el comienzo del fin de esta corriente político-ideológica, que daría sus últimos estertores en los albores de los años 1930s. Ligado a este primer rasgo, encontramos que en su gran mayoría las investigaciones, tanto generales como particulares, no trascienden los límites del experimento forista ${ }^{2}$ como experiencia anarquista en el movimiento obrero. Asimismo notamos que del conjunto de trabajos sobre la temática emerge un eufemismo que, por medio de una violentación semántica, establece lo capitalino como "nacional". Así la mayor parte de las pesquisas son referidas a las experiencias capitalinas y/o realizadas con fuentes de carácter "nacional", como por ejemplo La Protesta, ${ }^{3}$ periódico que si bien no desdeñaba la información referida a sucesos ocurridos fuera de la Capital, se remitía a tratarlos marginalmente. Otra faz de aquel scH está vinculada a la dinámica que dicha corriente le imprimó a los conflictos obreros en los cuales tuvo un papel dirigente, resumidos en la frase "todo o nada" que im-

\footnotetext{
${ }^{1}$ El ejercicio revisionista, si es válido para la experiencia argentina, quizás pueda ser extensible, aunque no asimilable, salvando las diferencias culturales, a la realidad latinoamericana. Esto será ensayado en próximos trabajos del autor.

2 Hacemos referencia a la Federación Obrera Regional Argentina (FORA), organismo políticosindical fundado en 1901 con el nombre de Federación Obrera Argentina, que hacia 1905 adhirió al comunismo anárquico y que en 1915 fue rebautizada con el nombre de FORA V ${ }^{\circ}$ Congreso, para diferenciarse de la FORA IX ${ }^{\circ}$ Congreso de tendencia sindicalista. Para mayor detalle véase Edgardo Bilsky, La FORA y el movimiento obrero, 2 tomos, Buenos Aires, CEAL, 1985.

3 Primeramente denominado La Protesta Humana (1897-1903), La Protesta es un periódico anarquista (de la corriente "organizadora") editado en la Ciudad de Buenos Aires (Argentina). Esta publicación que comenzó siendo quincenal, en 1904 pasó a editarse diariamente, con una tirada aproximada de entre 4.000 y 8.000 ejemplares. Hacia 1910 la tirada llegó a los 16.000 ejemplares. Para más detalle véase Juan Suriano, Anarquistas. Cultura y política libertaria en Buenos Aires, 189o1910, Buenos Aires, Manantial, 2001. En particular su capítulo V "La prensa anarquista”, pp.179215.
} 
plicaba la negación sistemática a cualquier tipo de negociación y, por ende, a la prolongación de las huelgas hasta que éstas triunfaran totalmente o fuesen derrotadas. Otro aspecto se vincula a la relación entre anarquismo y Estado. Así, si por un lado, se considera que los anarquistas descartaban la mediación estatal como forma de resolución de los conflictos entre capital y trabajo; por otro lado, y como consecuencia, se supone que la única acción estatal posible hacia dicho sector era la represión. Finalmente, aunque no menos importante, es común encontrar en las diversas publicaciones sobre la problemática anarquista una identificación mecánica entre esta ideología "arcaica", una organización por oficio y un proceso de trabajo poco desarrollado, artesanal. La línea de análisis es: artesano-oficio-anarquismo (como ideología pre-moderna); a la cual se le contrapone esta otra línea de análisis: obrero de la gran industria-sindicatos únicos por rama-comunismo (como ideología moderna). Dicho esto queda por adelantar de qué forma abordaremos tan espinosa tarea de revisión historiográfica. La labor revisionista será desarrollada a la luz de, y en tensión con, las acciones de lucha, negociación y organización experimentadas por un conjunto heterogéneo de obreros y obreras de distintos gremios que tuvieron como denominador común encontrarse nucleados y dirigidos por grupos anarquistas de las Juventudes Libertarias (JJLL) y de la Federación AnarcoComunista Argentina (FACA), ${ }^{4}$ en un territorio singular, Mar del Plata, ${ }^{5}$ durante un período particular, los primeros años de la década de 1940.

\section{Fragmentos ilustrativos del sentido común historiográfico sobre el anarquismo}

Nuestra lógica pretende ser la de un pensar poético, heterogeneizante, inventor o descubridor de lo real. Que nuestro propósito sea más o menos irrealizable,

\footnotetext{
${ }^{4}$ La FACA fue fundada en 1935, luego de dos importantes congresos anarquistas (1931 y 1932), su antecesora fue el Comité Regional de Relaciones Anarquistas (1932). En 1955 pasó a llamarse Federación Libertaria Argentina. Acción Libertaria (desde 1933) es su órgano de prensa. Las JJLL son parte de la FACA.

${ }^{5}$ La ciudad-puerto de Mar del Plata se encuentra ubicada en el litoral del mar argentino, en el sureste de la provincia de Buenos Aires. Es la cabecera del partido de General Pueyrredón y una de las ciudades turísticas más importantes del país. Está ubicada 404 kilómetros al sureste de la Ciudad de Buenos Aires, capital de la Argentina.
} 
en nada amengua la dignidad de nuestro propósito. Más si éste se lograre algún día, nuestra lógica pasaría a ser la lógica del sentido común.

Juan de Mairena Antonio Machado

Quisiéramos aclarar que si bien, y quizás exageradamente, nos detendremos en desmenuzar lo que entendemos y llamamos SCH sobre "el anarquismo argentino", la monumental labor investigativa y de recopilación de los autores aquí inquisidados trasciende ampliamente los límites del SCH y crea las condiciones de posibilidad de nuestra crítica. Dicho esto, pasemos a dar una breve y precaria definición de $\mathrm{SCH}$.

Según entendemos, el scH refiere a aprehensiones de varios historiadores de centralidad destacada en el campo, con la idea de un "acuerdo universal" respecto a ciertas "verdades" que se suponen aceptables para todos y evidentes por sí mismas. Debido a que este tipo de conocimiento se basa en la tradición o consenso de la mayoría, en el acuerdo común de quienes lo comparten y utilizan, y que es guardián; hacer entrar una nueva "verdad" en él es verdaderamente difícil. Por su parte, el proceso reproductivo de aquellas verdades autoevidentes es llevado adelante por todos aquellos que, consciente o inconscientemente, se contentan con repetir y comentar la palabra de los maestros a través de una suerte de circuito intelectual en el que transitan palabras clave y frases un poco reduccionistas. Así el SCH se vuelve una concepción general absorbida acríticamente por diversos ambientes historiográficos en los cuales se moldea el historiador medio. Y, vale aclarar, todo este juego se genera, desarrolla y regenera, no prescindiendo pero sí con independencia de las voluntades implicadas, es decir que, lejos de toda simplificación psicologista, el SCH nunca es una configuración diseñada para tal fin. Ahora veamos cómo se metamorfosea este SCH en comunión con "el anarquismo argentino".

Como adelantáramos en la introducción, comenzaremos la revisión por el corte temporal de la experiencia anarquista que coagula en el scH sobre el anarquismo. Así podremos observar que los libros que son referencia obligada en el campo establecen una periodización que oscila entre las décadas de 1870 y 1930. Ahora bien, este corte temporal, aunque fue adoptado rápidamente por la historiografía, tiene su origen allende las fronteras académicas. El texto fundante de este y otros rasgos del SCH sobre el anarquismo es La FORA. Ideología y trayectoria del movimiento obrero revolucionario en la Argentina, de Diego Abad de Santillán que, publicado por primera vez en 1932, sentó las bases para la posterior traslación 
de la historia oficial anarquista hacia el corazón de la historiografía académica. ${ }^{6}$ No obstante, el primer libro sobre "el anarquismo argentino", si bien se sitúa fuera del relato anarquista autorreferencial y apologético, no responde a las prácticas normalizadas de la disciplina historiográfica. ${ }^{7}$ Así, Los Anarquistas de Hugo del Campo, publicado en 1971 como tomo 56 de la colección "La Historia Popular. Vida y milagros de nuestro pueblo" del CEAL y considerable como explícitamente político y de alta divulgación, delimita la temporalidad de la experiencia anarquista, siguiendo los lineamientos de la narrativa santillanista, entre 1879 y $1930 .{ }^{8}$ Según nos cuenta nuestro autor, luego de variados y efímeros intentos de consolidación durante los últimos años del siglo XIX, el anarquismo argentino llegó a su madurez hacia principios del siglo xx, manteniéndose como tendencia dominante en el movimiento obrero a lo largo de una década. Pero, hacia mediados de la década de 1910 -nos sigue diciendo del Campo- por primera vez los anarquistas quedaron en minoría dentro del movimiento obrero y, años más tarde, los sucesos de enero de 1919 significaron el principio del fin de la influencia anarquista en el movimiento obrero. Finalmente, en las últimas dos oraciones del último párrafo del libro, el autor afirma sobre el anarquismo argentino que "la violenta represión que siguió al golpe de Uriburu le dio el golpe de gracia. En el país posterior al 30 no había sitio para ellos". ${ }^{9}$ Más adelante veremos que esto no fue así, pero ahora sigamos con nuestro relato. Pivoteando entre una narrativa explícitamente política y otra en los umbrales de la normalización historiográfica contamos con los trabajos de Osvaldo Ba-

\footnotetext{
${ }^{6}$ Diego Abad de Santillán, La FORA. Ideología y trayectoria del movimiento obrero revolucionario en la Argentina, Buenos Aires, Libros de Anarres, 2005. El autor es considerado uno de los más importantes, sino el más, referentes del anarquismo en Argentina. Nacido en una aldea de León (España) en 1897 hacia 1905, junto a su familia, emigra hacia Argentina. En este país se destacó como dirigente, intelectual e historiador del movimiento anarquista local. Para más detalles véase Horacio Tarcus (dir.), Diccionario biográfico de la izquierda argentina. De los anarquistas a la "nueva izquierda" (1870-1976), Buenos Aires, Emecé, 2007, pp.1-3.

${ }^{7}$ Para un tratamiento de estas prácticas aunque sobre otra temática y período, véase Omar Acha y Nicolás Quiroga, "Pliegues de la normalización de los estudios sobre el primer peronismo: complementos y aclaraciones”, en Raanan Rein, Carolina Barry, Omar Acha y Nicolás Quiroga (eds.), Los estudios sobre el primer peronismo. Aproximaciones desde el siglo XXI, La Plata, 2009, pp. 81-102. Siguiendo a los autores podemos decir que la normalización es equivalente a una estandarización, o sea, la imposición de una norma de construcción de las narrativas históricas.

${ }^{8}$ Hugo del Campo, Los Anarquistas, Buenos Aires, CEAL, 1971.

${ }^{9}$ H. del Campo, Los Anarquistas, p.114. Cursivas nuestras.
} 
yer, ${ }^{10}$ Julio Godio, ${ }^{11}$ Edgardo Bilsky, ${ }^{12}$ Iaacov Oved ${ }^{13}$ y los primeros trabajos de Juan Suriano, ${ }^{14}$ entre otros. Más cercanos en el tiempo y con un relato "sujetado" por la profesionalización historiográfica, contamos con los estudios de Dora Barrancos, ${ }^{15}$ Gonzalo Zaragoza Ruvira ${ }^{16}$ y los más recientes de Juan Suriano, ${ }^{17}$ entre

${ }^{10}$ Véase Osvaldo Bayer, Severino Di Giovanni, el idealista de la violencia, Buenos Aires, Galerna, 1970; La Patagonia rebelde, 2 tomos, Buenos Aires, Página/12, 2009.

11 Véase Julio Godio, La Semana Trágica de enero de 1919, Buenos Aires, Hyspamérica, 1985; El movimiento obrero argentino (1870-1910). Socialismo, anarquismo y sindicalismo, Buenos Aires, Legasa, 1987.

12 Véase Edgardo Bilsky, La FORA.

${ }^{13}$ Véase Iaacov Oved, El anarquismo y el movimiento obrero en Argentina, México, Siglo XXI, 1978. También pueden consultarse del mismo autor los siguientes artículos: "El trasfondo histórico de de la Ley 4.144 de Residencia”, en Desarrollo Económico vol.6, n. ${ }^{\circ} 61$, Buenos Aires, 1976, pp.123-150; "Influencia del anarquismo español sobre la formación del anarquismo argentino", en EIAL, [online], vol. 2, n. ${ }^{\circ}$ 1, enero-junio 1991, http://www.tau.ac.il/eial/II_1/oved.htm; [citado 27 Julio 2011]. "The Uniqueness of Anarchism in Argentina", en EIAL [online], vol.8, n. ${ }^{\circ} 1$, enero-junio 1997. http://www.tau.ac.il/eial/vIII_1/oved.htm. [citado 27 Julio 2011]. Si bien el autor en sus estudios se ocupó de los primeros años del anarquismo en Argentina, aproximadamente hasta 1905, en este último trabajo explicita el período completo de vigencia de esta corriente político-ideológica en el país como actor de relevancia, dice: "As an active movement, with its own institutions and publications, anarchism existed uninterrupted in Argentina for about fifty years, between 1880 and 1930." Pero aclara que mientras "by the end of 1910, anarchism had started to show clear signs of fatigue" con los sucesos de la Semana Trágica "the decline of anarchism continued", para concluir diciendo que "From 1922, the anarchist movement experienced a steady descent towards marginality. This decline was compounded by schisms, banditry and terror, epitomized by the Severino de Giovanni affair. Eventually, internal strife and persecution led to its demise, just before the Uriburu coup in 1930". Cursivas nuestras.

14 Véase Juan Suriano, Movimientos sociales: la huelga de inquilinos de 1907, Buenos Aires, CEAL, 1983; Trabajadores, anarquismo y Estado represor: de la Ley de Residencia a la de Defensa Social (1902-1910), Buenos Aires, CEAL, 1988. En este último el autor adelanta la imagen del ocaso anarquista en torno a los sucesos del Centenario y nos dice: "En este contexto la represión gubernamental -a través de las deportaciones y otras manifestaciones- logró su objetivo de desarticular e impedir la relaciones de los trabajadores y los libertarios, más allá de los estertores de la Semana Trágica”. p.29.

${ }_{15}$ Dora Barrancos, Anarquismo, educación y costumbres en la Argentina de principios de siglo, Buenos Aires, Contrapuntos, 1990.

16 Gonzalo Zaragoza Ruvira, Anarquismo Argentino, Madrid, Eds. de la Torre, 1996.

17 Véase Juan Suriano, "Ideas y prácticas políticas del anarquismo argentino”, en Entrepasados n. ${ }^{\circ}$, comienzos de 1995, pp.21-48; "Las prácticas políticas del anarquismo argentino", en Revista de Indias vol.LVII, n. $^{\circ}$ 210, Madrid, CSIC, 1997, pp.421-450; Juan Suriano, "El anarquismo", en Mirta Z. Lobato (dir.), El progreso, la modernización y sus límites, 1880-1916, Buenos Aires, Sudamericana, 2000, pp. 291-325; "La oposición anarquista a la intervención estatal en las relaciones labora- 
otros. Todos estos trabajos colaboraron en la construcción de una imagen historiográfica de "el anarquismo argentino" sobre el molde temporal del relato de su fracción forista, empero en las próximas líneas haremos eje principalmente en los trabajos del último de estos historiadores, debiéndose esta selección a su centralidad en el campo y al refinamientos de su obra. Si bien el autor tiene trabajos previos sobre la temática, podemos decir que la obra cumbre, tanto para el campo de estudios sobre el anarquismo como para la trayectoria de Suriano, es Anarquistas. Cultura y política libertaria en Buenos Aires, 1890-1910 [2001], de carácter enciclopédico y para especialistas, secundada por Auge y caída del Anarquismo. Argentina, 1880-1930 [2005], que, pensada como de divulgación y por lo tanto para el gran público, se vende, como parte de una colección, en kioscos de diarios y revistas.

Pero antes de adentrarnos en su análisis quisiéramos mencionar que, aunque parezca paradójico, la primera obra en la que se habla de un SCH en la narrativa histórica sobre el anarquismo es en Anarquistas, de J. Suriano. Dice el autor: "como ha ocurrido con cualquiera de las versiones canónicas de la historia argentina desde Bartolomé Mitre en adelante, es notable la perdurabilidad de algunos supuestos básicos presentes en versiones militantes, que siguieron formando parte del sentido común historiográfico sin la corroboración empírica adecuada”. ${ }^{18}$ Justamente este aspecto, sumado a la relevancia de la obra, vuelve más interesante su revisión crítica desde parámetros compartidos. El mismo ejercicio que el autor realizó con obras precedentes será efectuado, seguramente sin la misma pericia, por nosotros con la suya. Esperamos que en algún momento nuestro trabajo merezca igual tratamiento.

Los títulos ya son ilustrativos de los límites temporales que se le han decretado a las experiencias anarquistas. Sin embargo, en la introducción a Anarquistas se nos brinda los porqués de ese recorte, escribe:

les”, en Juan Suriano (comp.), La cuestión social en Argentina 1870-1943, Buenos Aires, La Colmena, 2000, pp.89-110; Anarquistas. Cultura y política libertaria en Buenos Aires, 1890-1910, Buenos Aires, Manantial, 2001; Juan Suriano, Auge y caída del Anarquismo. Argentina, 188o-1930, Buenos Aires, Capital Intelectual, 2005. La misma editorial lanzó en el 2009 una nueva edición del libro.

${ }^{18}$ J. Suriano, Anarquistas, p.23. Cursivas nuestras. 
El límite temporal no es caprichoso, la fecha de inicio se ubica en torno a 1890, el momento en que comenzaban a hacerse evidentes los efectos sociales del proceso de modernización, y la propaganda libertaria empezaba a tomar cuerpo conformando sus primeros grupos, editando sus periódicos iniciales y delineando las estrategias que adoptaría el anarquismo maduro una década más tarde. Finalizar la investigación en 1910, aunque a veces se prolongue hasta 1912 o 1913, no implica que el anarqui7smo haya desaparecido, sino que esa fecha es el punto de partida de la decadencia, pues aunque el imaginario colectivo haya seguido percibiéndolo como un actor social de peso, en la práctica (política, social y cultural) desde 1910 había iniciado su inexorable declive. ${ }^{19}$

Inmerso en la densa reconstrucción histórica de las prácticas políticas del anarquismo, el autor insiste una vez más en el carácter terminal del anarquismo en los tempranos años de la década de 1910 sosteniendo que "la crisis política del orden conservador fue la crisis política del movimiento libertario". ${ }^{20}$ Ya en las páginas finales de Anarquistas encontramos la siguiente frase: "Si bien la 'bestia' no había muerto, es indudable que el anarquismo no podría subsanar las heridas recibidas y no recuperaría jamás el rol protagónico adquirido durante esa fugaz y tumultuosa primera década del siglo". ${ }^{21}$ Ya que "a diferencia de lo ocurrido durante la aplicación de los estados de sitio anteriores, en esta oportunidad su prolongada efectivización dañó seriamente la continuidad de las actividades y de las instituciones libertarias". 22 Por esto "cuando hacia la segunda mitad de 1913 los efectos de la represión habían concluido, el anarquismo era otro y la sociedad porteña había comenzado a transitar ciertas transformaciones que, aunque imperceptibles para los contemporáneos, desempeñaron un rol determinante en la decadencia del anarquismo". ${ }^{23}$ Así "después del Centenario el anarquismo ya no pudo articular una propuesta atractiva para los trabajadores. El anarquismo urbano argentino fue un fenómeno notable pero efímero...". ${ }^{24}$ Citas como las precedentes podrían multiplicarse, sin embargo consideramos que alcanzan para demostrar cómo el autor, a

\footnotetext{
${ }^{19}$ J. Suriano, Anarquistas,p.17. Cursivas nuestras

${ }^{20}$ J. Suriano, Anarquistas, p.286.

${ }^{21}$ J. Suriano, Anarquistas, p.335.

22 J. Suriano, Anarquistas, p.336.

${ }^{23}$ J. Suriano, Anarquistas, p.337.

${ }^{24}$ J. Suriano, Anarquistas, p.342. Cursivas nuestras.
} 
la vez que nos ilustra la forma en la que "el anarquismo urbano argentino" comenzaba a transitar su decadencia, también va cimentando las bases del SCH en lo que respecta a la temporalidad anarquista. Estos argumentos son tributarios de una teoría de la historia etapista que, en general, se encuentra nutrida por las ideas europeas de la modernidad política. Esta teoría desarrollista tiene al menos dos variantes, "el todavía no" y lo que nosotros llamaremos "el ya no". ${ }^{25}$ Según esta última deriva "el anarquismo argentino" ya había cumplido su etapa (una imagen biologícista de nacimiento -1870/1900-, desarrollo -1900/1910 y muerte -1910-1930), de esta forma "el anarquismo argentino" ya no tenía lugar es la Historia del movimiento obrero argentino.

Pasemos ahora a ver de qué forma algunos historiadores entrelazan, ligan y encorsetan las narrativas de la temporalidad anarquista con el experimento forista como experiencia ácrata en el movimiento obrero por antonomasia. Según nos cuentan, luego de un primer momento de fluencia y competencia entre distintas corrientes anarquistas, destacándose la ocurrida entre organizadores y antiorganizadores, se pasó a una fase o etapa de monopolio exclusivo de la línea que cristalizó en el tándem ideológico-organizativo conformado por el periódico $L a$ Protesta y la FORA. Así este bloque hegemónico excluyó y ocluyó todo atisbo de expresión anarquista divergente hasta el fin de sus días, generando de esta forma la imposibilidad de la perpetuación del anarquismo por fuera de lo que fue la experiencia forista, dando lugar a que fuese reemplazado en el seno de la clase obrera y los sectores explotados del pueblo por otras corrientes político-ideológicas (sindicalimo-socialismo-comunismo). Según del Campo desde comienzos del siglo xx el sindicalismo anarquista "eclipsó totalmente a las tendencias antiorganizadoras". ${ }^{26}$ Ya maduros -sigue diciendo el autor- y "nucleados en la FORA", "los anarquistas impulsaron la organización de los trabajadores". ${ }^{27}$ Esta identificación entre FORA y "anarquismo argentino" continúa en las páginas siguientes, cuando el autor después de referirse al $\mathrm{v}^{\mathrm{o}}$ Congreso de la FORA dice que "la identificación ideológica

\footnotetext{
${ }^{25}$ Para un tratamiento de estas y otras problemáticas de la historiografía véase Dipesh Chakrabarty, Al margen de Europa. ¿Estamos ante el final del predominio cultural europeo?, Barcelona, Tusquets, 2008.

${ }^{26}$ Hugo del Campo, Los Anarquistas, p.73.

${ }^{27}$ H. del Campo, Los Anarquistas, p.83.
} 
con el sindicato" es la "peculiaridad del anarquismo argentino". ${ }^{28}$ También encontramos esta equivalencia en los otros autores, por ejemplo, Suriano al referirse a la disputa con los sindicalistas expresa que "los anarquistas, abroquelados en la FORA, resistieron". ${ }^{29}$

Como adelantáramos en la introducción, luego de dar a entender, de diversas formas, que las fronteras argentinas son el límite socio-espacial de sus investigaciones sobre el anarquismo, estos estudios, en su gran mayoría, no trascienden las fronteras de la Capital Federal, ${ }^{30}$ no por esto dejan de insistir en su generalización. Fue así que se dio lugar al eufemismo que establece lo capitalino como "lo nacional", "lo argentino". Esta práctica historiográfica, que no es privativa de los trabajos sobre anarquismo, se ve fortalecida por el uso casi exclusivo que realizan los historiadores de las fuentes de pretendido carácter "nacional". En Anarquistas Suriano desde el subtítulo aclara que su investigación se acota a la ciudad de Buenos Aires, sin embargo repetidas veces hacer referencia al "anarquismo argentino". Ya desde el índice podemos ver cómo el recorte espacial se desplaza de lo local a lo nacional, cuando en los capítulos VI y VII habla de "anarquismo argentino". Por otra parte, a lo largo del libro no hay capítulo en el que no se pase de la caracterización del "anarquismo porteño" a la del "anarquismo urbano argentino". Veamos en que fuentes se basan estas generalizaciones: de las 25 publicaciones periódicas citadas todas son de capital. Pero, fijémonos ahora en que proporción fueron citadas cada una de las mismas a lo largo del libro: de un total de 481 citas de publicaciones periódicas 447 corresponden a 23 publicaciones anarquistas y las 34 citas restantes corresponden a la prensa comercial. Mientras 22 de las 23 publicaciones anarquistas se reparten la cantidad de 170 citas (a razón de 8 por publicación), la restante concentra la cantidad de 277 citas. Esa publicación es La Protesta. Esto nos lleva a plantear la necesidad de quitarle el pretendido carácter nacional a las investigacio-

\footnotetext{
${ }^{28}$ H. del Campo, Los Anarquistas, p.94.

${ }^{29}$ J. Suriano, Auge y caída, p.61.

${ }^{30}$ Cuando lo hace se acota a registrar los alcances de de alguna lucha que tuvo su epicentro en la capital o refiere a alguna ciudad importante del litoral y la zona pampeana.
} 
nes centradas en la Ciudad de Buenos Aires, nos sugiere la necesidad de "provincializar" la capital federal. ${ }^{31}$

Otro aspecto caro a los estudios sobre anarquismo refiere a los rasgos que los libertarios le imprimieron a los conflictos obreros en los cuales tuvieron un papel dirigente. Identificados con la acción directa, con la huelga general como estandarte, y pintados como incondicionalmente radicalizados, los anarquistas -según el SCH- habrían desarrollado en los conflicto obreros una política de "todo o nada", lo que implicaba la negación sistemática a cualquier tipo de negociación y, por ende, a la prolongación de las huelgas hasta que éstas triunfaran totalmente o fuesen derrotadas. Esta visión no sólo se nutrió de los relatos canónicos del anarquismo sino también, quizá más relevante, de los relatos también canónicos de sus oponentes, que es el caso de los socialistas. En la obra de Suriano leemos que "la idea del todo o nada, de alcanzar sus objetivos en forma inmediata teñía las expectativas de gran parte de los anarquistas", 32 también sostiene que los anarquistas "en general despreciaban la negociación y privilegiaban la idea del todo o nada". 33

Por su parte, la relación de esta corriente político-ideológica con el Estado es caracterizada por los historiadores como confrontativa, siendo el enfrentamiento la única estrategia posible, tanto para los anarquistas como para el Gobierno. Según nos cuenta Suriano "ante la rígida oposición al Estado y a cualquier forma de integración política por parte del anarquismo, los grupos gobernantes adoptaron una postura no menos rígida y decidieron implementar una política de exclusión del anarquismo". ${ }^{34} \mathrm{Si}$ por un lado, algunos investigadores consideran que los anarquistas descartaban la mediación estatal como forma de resolución de los conflictos laborales, por otro lado, y consecuentemente, suponen que la única acción estatal posible hacia los libertarios era la represión. Al igual que en la anterior, esta visión se reforzó por medio del relato socialista. En palabra del autor de Anarquistas, "el anarquismo no quería ni podía aceptar esta mediación [del Estado] en tanto lo con-

${ }^{31}$ La idea de "provincializar" ciertos criterios pertendidos universales (generales), quizás se más pertinente en nuestro caso "municipalizar", la tomamos prestada de Dipesh Chakrabarty, Al margen de Europa.

32 J. Suriano, “Anarquistas, p.299.

${ }^{33}$ J. Suriano, Auge y caída, p.14.

${ }^{34}$ J. Suriano, Anarquistas, p.20. 
sideraba representante de los sectores patronales". 35 "El anarquismo no aceptó ni aceptaría jamás este rol [interventor] pues consideraba al estado representante y defensor de los intereses de una de las partes. Optó por seguir orientando sus luchas por los carriles de la acción directa y la negativa a la negociación con el estado". 36

Finalmente, nos llama la atención la perdurabilidad de un relato que, más o menos sofisticadamente, identifica de forma mecánica fenómenos políticoideológicos, organizativos y culturales con fenómenos de índole estructural, económica. De esta forma se construye una correspondencia entre el anarquismo como ideología "arcaica", con una organización por oficio y un proceso de trabajo poco desarrollado, artesanal. Un ejemplo extremo de este rasgo del $\mathrm{sCH}$ lo encontramos en el trabajo de Héctor Cordone, quien sostiene que "el anarquismo prevaleció entre los numerosos trabajadores del sector artesanal", ${ }^{37}$ pero que a partir del desarrollo y modernización industrial de las décadas de los años 1920s y 1930 y la emergencia de "la figura del obrero moderno en desmedro del antiguo artesano" se acentuó la decadencia del anarquismo cuyas propuestas ya no encontrarían eco en los nuevos contingentes obreros". ${ }^{38}$ Otro ejemplo, aunque no tan extremo como el precedente, es el de J. Suriano, aunque alertado sobre la inconveniencia de "esquematizar y simplificar en demasía la vinculación entre ideologías y clase sociales" ${ }^{39}$ convive con esta faz del SCH cuando sostiene que así como su amplitud conceptual "le permitió al anarquismo aprovechar la coyuntura de desorden propia de la formación de la estructura social y el carácter embrionario del movimiento obrero, más adelante se tornaría negativa" debido a las "modificaciones relacionadas con la incipiente industrialización". ${ }^{40}$

\footnotetext{
35 J. Suriano, Auge y caída, p.20.

${ }^{36}$ J. Suriano, Anarquistas, p.263.

37 Héctor Cordone, "Reflexiones sobre movilizaciones populares y movimiento obrero argentino durante el primer peronismo (1946-1955)", en Sociología del Trabajo n. ${ }^{\circ} 6$, Buenos Aires, Piette, 2000, p.3.

${ }^{38}$ H. Cordone, "Reflexiones sobre movilizaciones populares", p.7.

${ }^{39}$ J. Suriano, Anarquistas, p.24.

${ }^{40}$ J. Suriano, Anarquistas, p.26.
} 


\section{2.- Anarquistas negociadores: experiencias de organización y lucha sindical en los años $1940 s$}

En este apartado, a partir de un conjunto de experiencias que la tendencia faquista del anarquismo experimentó en el seno de la clase obrera sobre el terreno marplatense durante los primeros años de la década de 1940, pretendemos ilustrar la forma en la cual esas prácticas pueden ser leídas como acciones que se desarrollaron a contrapelo de lo que los grandes relatos historiográficos sobre el anarquismo creen son los rasgos distintivos de "el anarquismo argentino". Con el siguiente ejercicio queremos también esbozar precariamente una crítica a lo que pensamos una forma particular de vocación universalista presente, explicita o implícitamente, en los historiadores. Pues, en estos casos la ilusión gnoseológica de buscar en lo particular la explicación de lo general adolece de una gran inconsistencia tautológica. A saber, en el mejor de los casos, estas prácticas se sustentan en un mecanismo que configura "lo general" a partir de los rasgos de "lo particular" que, previamente al análisis de "lo particular", fueron proyectados sobre un recorte temporal y/o espacial más amplio ("lo general"), una vez conjurado este momento se pasa al análisis de lo particular, para luego concluir con la más que probable correspondencia entre lo uno y lo otro. En el peor de los casos, esta identificación se da sin previa mediación adjudicándole a lo particular el carácter de "lo general". Es así como se genera un relato tensionado por la unilateralidad y la unidimensionalidad, que alisa la textura corrugada de los procesos históricos que finalmente, produciendo una momificación del cuerpo social, establece las coordenadas de una narrativa ahistórica. Es por lo antedicho que la reconstrucción histórica que emprenderemos en los párrafos siguientes no tiene la intención de elaborar claves para una renovada explicación general de "el anarquismo argentino". No buscamos la piedra de toque que nos permita definir/delimitar de una vez y para siempre los atributos distintivos del "anarquismo argentino" que trascienden los marcos temporales y espaciales, no buscamos lo homogéneo. Sin renunciar a la pretensión de un relato histórico totalizante y global como construcción colectiva, hurgamos en aquellas experiencias anarquistas con la finalidad de oxigenar el apelmazado relato historiográfico desde una perspectiva heterogeneizante.

Desde una perspectiva historiográfica más triunfalista que institucional, los relatos históricos hegemónicos, ya estén centrados en las corrientes de izquierda o en el mundo de los trabajadores, han establecido una periodización para los años 
pre-peronistas que, con algunas variantes en los años, consta de cuatro momentos consecutivos, en los cuales determinada corriente político ideológica ejerció su hegemonía sobre el movimiento obrero y el resto de las tendencias. Así, en una primera etapa la hegemonía le correspondió a los anarquistas, en una segunda a los sindicalistas, luego a los socialistas y finalmente a una combinación entre estos últimos y los comunistas. Al igual que a alguien que esté intentando rastrear la autonomía de las cúpulas sindicales peronistas o la supervivencia de corrientes sindicales de izquierda durante los dos primeros gobierno de Perón (1946-1955), ${ }^{41}$ tratarían de despistado o de neófito en el tema a aquel que busque la importancia del anarquismo en el movimiento obrero con posterioridad al golpe de Uriburu. ${ }^{42} \mathrm{Ya}$ sabemos que "en el país posterior a 1930 no había sitio para ellos". 43

Sin embargo, a riesgo de quedar como un confundido más, acompañaremos con nuestro relato a aquellos anarquistas que acometieron la difícil tarea de sobrevivir a la represión material del régimen de Uriburu y a la violencia simbólica de la historiografía desarrollista, y que fueron capaces de desarrollar una intensa tarea de militancia, organización, lucha y negociación, contra los pronósticos historiográficos de "el ya no". Anarquistas, obreros/as, vecinos/as, patrones, gobiernos y Estados fueron alguno de los extremos de las relaciones sociales que se anudaron, y difícilmente podamos delimitar entre ellos a aliados y enemigos, ya que estos papeles se fueron intercambiando en el transcurso del proceso histórico elegido para este estudio.

La década de 1930, con su agudo proceso de desarticulación-rearticulación de relaciones sociales en el plano económico, político-institucional, ideológico y cultural, significó un momento de abrupto cambio en la fisonomía de la sociedad argentina, que no era ajena a los procesos mundiales. Pero, como es de suponer, este proceso global no fue homogéneo. La Argentina, al igual que todas las sociedades nacionales, no fue un caso más, pero tampoco una excepción, en la reconfiguración global del capitalismo mundial. Esta situación se reiteraba a escala regional

\footnotetext{
${ }^{41}$ El peronismo es un movimiento de masas y popular surgido entrada la década de 1940 que tomó su nombre de la figura del militar nacionalista Juan Domingo Perón. Comúnmente se lo engloba como parte de los fenómenos populistas latinoamericanos.

42 José Félix Uriburu fue uno de los líderes militares del golpe de estado de 1930 y presidente de facto entre 1930 y 1932. Su gobierno, enmarcado en ideales filo fascistas, se destacó en el campo obrero por una dura represión, en particular contra comunistas y anarquistas.

${ }^{43}$ H. del Campo, Los Anarquistas, p.114.
} 
(municipal y/o provincial), donde la comunidad local se vio refigurada como producto de un proceso de resistencia-adaptación al proceso "nacional", proceso con pretensiones homogeneizantes pero finalmente heterogéneo. Permeados, en mayor o menor grado, por estas transformaciones sociales, los anarquistas siguieron siendo protagonistas de la historia argentina post golpe de 1930. Viejas y nuevas federaciones, antiguas y noveles formas organizacionales, se encontraron y desencontraron durante aquella década. En Mar del Plata, la Federación Obrera Local (adherida a la FORA V $V^{0}$ Congreso) dejaría su lugar a la Unión Obrera Local de Sindicatos Autónomos (adherida a la FACA) y la organización por oficio iría cediendo su preeminencia a la organización por industria. La confluencia de una nueva generación de militantes anarquistas y de una nueva generación de obreros/as dejó una profunda huella en la historia de las luchas sociales de la ciudad. Es este pequeño fragmento de la historia el que pretendemos rescatar del olvido.

El inicio de la década del cuarenta parce ser un momento clave para los protagonistas de esta historia, y esto por varias razones. Entre el 7 y el 9 de julio de 1940 se desarrolló el Segundo Congreso Ordinario de la FACA, en el cual, luego de acaloradas discusiones, se votaron las resoluciones. En la introducción a las mismas se realiza, entre otras cosas, un análisis de la situación del movimiento obrero en la Argentina en el que se sostiene que:

Nadie puede desconocer que la situación general actualmente imperante y particularmente la que nos ofrece el ambiente obrero es absolutamente distinta a la que existía hace unas décadas, cuando se elaboraron y tomaron auge los métodos de acción, normas orgánicas y consignas del movimiento obrero anarquista en el país. Por considerarlo obvio, no examinamos en detalle las grandes diferencias en el orden moral y material que separan esas distintas épocas desde el punto de vista de la lucha obrera. Sería absurdo pues continuar repitiendo fórmulas y querer seguir aplicando procedimientos absolutamente reñidos con las posibilidades y las necesidades del momento, ya que no se trata de cuestiones abstractas sino de acciones concretas y cotidianas. ${ }^{44}$

Para enterarnos a que se estaban refiriendo concretamente sigamos con la lectura de la introducción: "en cuanto a la absurda negativa de aceptar nuevas for-

\footnotetext{
${ }^{44}$ FACA, Resoluciones del Segundo Congreso Ordinario, Buenos Aires, 7, 8 y 9 de julio de 1940, p.1.
} 
mas de estructuración sindical, impuestas por la evolución industrial; en cuanto impedía el aprovechamiento de ciertas conquistas necesarias a los trabajadores, por el hecho de que dichas conquistas estaban consagradas por sanción legal. Y muchos otros errores...”. ${ }^{45}$ También en la introducción se realiza una caracterización de las centrales obreras existentes, considerando burocráticas a la CGT y a la USA y sectaria a la FORA. Esta caracterización determinó recomendar "como lugar preferente de actuación el movimiento obrero autónomo". ${ }^{46}$ Además, se resolvió "propiciar la organización por industria en las ramas de la producción cuyo desarrollo lo haga posible", ${ }^{47}$ y aclara que "la adopción de esa norma estructural en el movimiento obrero, no implica de ningún modo el abandono de la organización de sindicatos de oficio, en las localidades y gremios que por sus características especiales hagan inútil o innecesaria la organización industrial”. ${ }^{48}$ Por otra parte, en las resoluciones se considera que si bien la intervención del estado debe ser resistida "no debe llegar al extremo de abandonar los sindicatos donde dicha intervención se acepte". ${ }^{49}$ Por último, quisiéramos destacar que en las resoluciones se consideró necesario impulsar la "creación de Uniones Obreras locales donde no existieran, como primera fase de la unidad del proletariado de cada lugar". ${ }^{50} \mathrm{Si}$ estas resoluciones programáticas prefiguran prácticas anarquistas disonantes con las imaginadas por el $\mathrm{scH}$, las prácticas a ras del suelo efectivamente realizadas por los y las anarquistas se distancia mucho más de aquel $\mathrm{SCH}$.

Aquella última resolución mencionada dio lugar a que en la ciudad de Mar del Plata se trabajara en ese sentido. Así, durante los primeros días del mes de agosto de 1940 quedó constituida la UOL. La iniciativa perteneció a obreros y obreras de cinco gremios dirigidos por militantes de la FACA, "pintores, electricistas, plomeros y cloaquistas, colocadores de mosaicos y mosaístas y Sociedad Unión Chauffeurs". ${ }^{11}$ En pocos meses la UOL creció vertiginosamente, de cinco pasó a 10 y

\footnotetext{
${ }^{45}$ FACA, Resoluciones del Segundo Congreso Ordinario.

${ }^{46}$ FACA, Resoluciones del Segundo Congreso Ordinario, p.2.

${ }^{47}$ FACA, Resoluciones del Segundo Congreso Ordinario.

48 FACA, Resoluciones del Segundo Congreso Ordinario.

49 FACA, Resoluciones del Segundo Congreso Ordinario.

${ }^{50}$ FACA, Resoluciones del Segundo Congreso Ordinario.

${ }^{51}$ Véase La Capital (LC), 09 de agosto de 1940, p.3.
} 
luego a 15, para finalmente oscilar entre 20 y 25 organizaciones adheridas. Muchos de estos sindicatos, incluidos los que fundaron la uoL, estuvieron agrupados previamente en la FOL, que para ese entonces era una fuerza existente pero exigua, sin embargo muchos otros fueron creaciones nuevas, como el Sindicato Obrero de la Industria de la Cerámica (SOIC), el Sindicato Obrero de la Industria del Pescado (SOIP) y el Sindicato Obrero de la Industria del Dulce (SOID), donde tuvieron un papel militante importante las JJLL de Mar del Plata. Esta entidad, integrante de la FACA, fue fundada en la ciudad durante el año 1941 por un grupo de jóvenes anarquistas que militaban en la UOL. Estas experiencias se desarrollaron en tensión, por un lado, con el apaciguamiento de la represión estatal y la disminución de la tasa de desocupación y, por otro lado, con la reactivación del movimiento obrero y la intervención y regulación estatal de las relaciones laborales. Entre 1935 y 1943 se firmaron en la ciudad más de cincuenta convenios de trabajo, concentrándose el 70\% en los últimos cuatro años. Convenios que en su gran mayoría fueron rubricados por el Departamento Provincial del Trabajo (DPT).

Tabla 1: Convenios colectivos 1935-1943

\begin{tabular}{|l|c|c|c|c|c|c|c|c|c|}
\hline & $\mathbf{1 9 3 5}$ & $\mathbf{1 9 3 6}$ & $\mathbf{1 9 3 7}$ & $\mathbf{1 9 3 8}$ & $\mathbf{1 9 3 9}$ & $\mathbf{1 9 4 0}$ & $\mathbf{1 9 4 1}$ & $\mathbf{1 9 4 2}$ & $\mathbf{1 9 4 3}$ \\
\hline \begin{tabular}{l} 
General Pueyrredón \\
\hline $\begin{array}{l}\text { Total Prov. Buenos Aires } \\
\text { (110 partidos) }\end{array}$
\end{tabular} & 21 & 49 & 133 & 159 & 104 & 127 & 172 & 269 & 230 \\
\hline Media por partido & 0,2 & 0,4 & 1,2 & 1,4 & 0,9 & 1,2 & 1,6 & 2,4 & 2,1 \\
\hline
\end{tabular}

Fuente: Elaboración propia en base a Ministerio de Gobierno, Anuario estadístico 1943, La Plata, 1944.

Haciendo referencia a esa situación, un editorial de La Capital decía:

En este último tiempo ha podido advertirse la saludable tendencia de los gremios obreros a tratar de buscar la solución de los conflictos del trabajo por los medios legales y en base a la intervención de los organismos del Estado. En es- 
tas columnas hemos venido destacando la pacífica solución de conflictos con la intervención eficaz del Departamento del Trabajo. ${ }^{52}$

Sin embargo, la mencionada "solución pacífica" fue más deseada que real. Muchos de estos convenios, como veremos, fueron precedidos por el desarrollo de todo tipo de conflictos obreros, siendo la huelga su expresión más cabal. Debemos aclarar que, si bien nosotros nos centramos en las experiencias anarquistas, aquella situación descripta por el editorialista era común al conjunto del movimiento obrero con independencia de sus corrientes político-sindicales. Comunistas, socialistas, sindicalistas y anarquistas, con diversos matices, hicieron uso compartido tanto de repertorios organizacionales y de lucha como de aliados. Pasemos a ver parte del universo experiencial anarquista.

Hacia mediados del mes de febrero, el secretario general de la Sociedad de Oficiales Peluqueros, Peinadores y Afines mediante un comunicado de prensa cuenta que dicha entidad gremial se dirigió a las autoridades locales y al director del DPT, Jorge Antigas, para informarles que los dueños de las peluquerías "violaban las leyes laborales" y hacían trabajar a sus empleados jornadas de 10 horas por un sueldo "miserable", y que desde que presentaron el pliego a los empresarios y a la Delegación Local del Departamento Provincial del Trabajo (DLDPT), ya hacía 90 días de esto, no obtienen respuesta alguna de sus patrones. Es por esto que decidieron declarar una huelga por 24 horas para el 18 de febrero. Sin embargo, el comunicado finaliza con espíritu conciliador, diciendo que "nosotros declaramos que nuestra finalidad es conseguir la firma del pliego mediante gestiones pero si la patronal persiste en su terca actitud, tendrá que responder de sus actos ante el consciente público y las autoridades que interpretan que lo que solicitamos, en justicia nos corresponde". ${ }^{53}$

Por su parte, algunos obreros organizados en sindicatos dirigidos por anarquistas apelaban a los oficios del gobierno local para la resolución de distintos problemas. Por caso el sábado 19 de septiembre la Sociedad Unión Chauffeurs remitió una nota al intendente municipal Manuel González Guerrico en la que se le solicitaba

\footnotetext{
${ }^{52}$ La Capital, 18 de septiembre de 1942

${ }^{53}$ La Capital, 17 de septiembre de 1942.
} 
ponga sus buenos oficios a fin de que sean ampliados los alcances de la ordenanza sancionada por el H. C. Deliberante, en el año 1934, aprobando los suplementos de tarifas a cobrarse en los viajes a la estación del ferrocarril, para que se hagan también efectivos cuando los viajes sean para la llegada o salida de los microómnibus, por entenderlo de justicia. ${ }^{54}$

En una solicitada publicada en la prensa local, que se enmarcaba en la lucha por la representación gremial entre anarquistas y comunistas, las obreras y obreros de la recientemente fundada Sociedad Obreros de Lavaderos Autónomos (anarquista), desmiente lo dicho por la Sociedad de Obreros de Lavaderos y Anexos (comunista) "por ser bajo todo punto de vista incierto y calumnioso, toda vez que tenemos tanta responsabilidad gremial como personal y que pertenecemos a la Sociedad Obreros de Lavaderos Autónomos, con sede en la Casa del Pueblo, la que fue fundada el 4 de septiembre del corriente año. Inmediatamente después fue confeccionado un pliego de condiciones con mejoras en los salarios, el que fue presentado al Sr. Armando Monjau y aceptado por el mismo, habiendo sido legalizado por el Departamento Provincial del Trabajo". ${ }^{5}$ Meses más tarde los entidades obreras otrora enfrentadas se unificaron en una organización por industrial. "Al producirse la fusión, constituyendo un solo organismo, toma este el nombre de Sociedad de Obreros Lavaderos, Planchado, Tintorería y Anexos (autónomo). Agrupa casi la totalidad de los obreros de la industria". ${ }^{56}$

Parte de este universo de experiencias se desarrolló en la industria de la construcción, en el marco de una intensa y larga lucha entre comunistas y anarquista por el reconocimiento, tanto por parte de la patronal como por parte del Estado, de sus respectivos sindicatos como únicas entidades sindicales representativas del gremio. Es así que en una nota enviada por la Sociedad de Albañiles y Peones Autónoma (anarquista) al Centro de Constructores de la ciudad, ante un conflicto intersindical que implicaba la paralización de una obra en construcción, los dirigentes gremiales libertarios apelaron a la ilegalidad de las acciones de "los extorsionistas" (los comunistas) diciendo que esas acciones fueron "en perjuicio de

\footnotetext{
${ }^{54}$ La Capital, 22de septiembre de 1942.

55 La Capital, 06 de diciembre de 1942. Cursivas nuestras.

${ }^{56}$ Solidaridad Obrera (SO) agosto 1943. Cursivas nuestras.
} 
los socios de esta Sociedad implicándose en el artículo 158 del Código Penal y 18 inciso E, de la ley 4548. (...) En cuanto a que el estar en conflicto con un socio de ese Centro es estarlo con todos los socios del mismo, entendemos que es una amenaza de Locout [sic] y que también es penado por la ley 4548". ${ }^{77}$ Después de varias idas y vueltas entre el Centro de Constructores, la Sociedad dirigida por los anarquistas y el Sindicato dirigido por comunistas, el viernes 8 de mayo autoridades platenses del DPT, el inspector general Dante Schenini y el inspector Carlos Álvarez Uzin, se hicieron presentes en la ciudad "para considerar la situación planteada por la existencia de gremios obreros antagónicos, cuyas divergencias tienen repercusión en las actividades de la construcción". 58 Por la tarde, en compañía de Diego Billourou Webber, jefe de la DLDPT, las autoridades del DPT mantuvieron una prolongada reunión con una delegación de la UOL "que se desarrolló en términos conciliatorios". ${ }^{59} \mathrm{Al}$ día siguiente, en una nueva reunión, las autoridades del DPT y del Centro de Constructores reconocieron a la Sociedad de Albañiles Autónoma como entidad gremial representativa de los obreros de la construcción.

Otro conflicto, que recibió con beneplácito el arbitraje del DPT y que culminó con la firma de un convenio colectivo de trabajo bajo la supervisión del Director del DPT Segundo V. Linares Quintana, fue el desarrollado entre el Sindicato de Obreros Carpinteros Autónomos (de dirección anarquista) y los dueños de las carpinterías adheridos al Centro de Constructores. Podemos leer en el convenio suscripto que "el incumplimiento será denunciado al Departamento del Trabajo por la parte afectada". ${ }^{60}$ Sin embargo, la firma del convenio no implico la culminación del conflicto pero sí su cambio de forma, ya no era más un conflicto obrero patronal ahora era una puja intersindical entre anarquistas y comunistas. La sección carpinteros y anexos del SOC (comunista) molesta por el triunfo logrado por los anarquistas del SOCA, comenzó sus gestiones ante las autoridades del DPT por un aumento del 10\% y el reconocimiento oficial del soc como único representante de los obreros carpinteros. Ante esta actitud el secretario general del socA manifiesta públicamente que

\footnotetext{
${ }^{57}$ La Capital, 19 de marzo de 1942. Cursivas nuestras.

${ }^{58}$ La Capital, o9 de mayo de 1942.

${ }^{59}$ La Capital, o9 de mayo de 1942.

${ }^{60}$ La Capital, 21 de junio de 1942.
} 
... este Sindicato se declara representante único de los obreros de la madera de esta ciudad; porque en las relaciones y condiciones de trabajo rige el contrato colectivo entre empleadores, es decir, dueños de talleres de carpinterías, y este sindicato un contrato refrendado por el Departamento Provincial del Trabajo, es decir, con toda fuerza legal. ${ }^{61}$

También otros sindicatos dirigidos por anarquistas aceptaron la intermediación del DPT. Ejemplo de ello fueron las organizaciones obreras de panaderos, de mucamas, de obreras del dulce, de obreros de la cerámica y de obreras del pescado. Estos últimos tres casos, sobre todo el último, serán analizados por separado por ser sindicatos nuevos, de tipo industrial, fundados con la intervención de las JJLL, afectos a negociar y relacionarse con el Estado provincial.

Sobre los primeros meses de 1942, convocados por la UOL y la Comisión Provisoria de Obreros de las Fábricas de Tejas, una gran cantidad de obreros jóvenes concurrieron a la asamblea constitutiva del gremio. Según nos relata el corresponsal de Solidaridad Obrera, "sin necesidad de hacer muchas consideraciones, todos comprendieron la necesidad de organizarse, dándose así forma definitiva al sindicato", que fue bautizado con el nombre de Sindicato Obrero de la Industria de la Cerámica. Luego se nombró una Comisión Administrativa que quedó encargada de "la confección de un pliego de condiciones y la convocatoria a una asamblea especial del gremio que deberá considerar dicho pliego, a fin de presentarlo oportunamente a los patrones". ${ }^{62}$ Finalmente el pliego fue aprobado por la asamblea obrera, aceptado por la patronal y rubricado por el DPT.

Hacia finales del año 1942, las obreras y obreros de la industria del dulce de la localidad, después de considerar las condiciones de trabajo en que se desenvolvían, jornadas laborales de hasta diez y once horas, cobrando las mujeres un salario que no pasaba de $\$ 3$ diarios y los hombres de $\$ 3,50$ a $\$ 4$, resolvieron confeccionar un pliego de condiciones que fue enviado a los patrones. El mismo exigía el reconocimiento del sindicato, las 8 horas de trabajo y el aumento salarial. ${ }^{63}$ A diferencia de los obreros de la cerámica, las obreras del soid necesitaron de una prolongada y

\footnotetext{
${ }^{61}$ La Capital, 11 de septiembre de 1942. Cursivas nuestras.

${ }^{62}$ Solidaridad Obrera, mayo 1942.

${ }^{63}$ Véase El Atlántico (EA), o6 de noviembre de 1942; Solidaridad Obrera, noviembre 1942.
} 
áspera huelga para obtener sus reivindicaciones, que se prolongó desde mediados de noviembre hasta fines de diciembre de 1942. La intransigencia del propietario de la granja El Grosellar y la fábrica de dulces La Dulsana, Oscar Plate, motivó las más indignadas declaraciones de las y los dirigentes anarquistas, que tildaron a este industrial de "nazi", "fascista" y "reaccionario" y lo acusaron de insultar y golpear a una obrera en huelga. ${ }^{64}$ Según el corresponsal de Solidaridad Obrera

...prácticamente no hubo traidores en esta huelga, pues los tres infelices que desde un principio quedaron en la fábrica, no pueden realizar ninguna labor de importancia. Los huelguistas están dispuestos a doblegar la intransigencia del fabricante, que tendrá que optar entre arreglar con el personal o dejar pudrir la fruta que está ya en plena madurez. En el momento de enviar esta breve crónica, se habla de posibilidades de arreglo. Si los hay, sólo habrán de consistir en la satisfacción de las justas demandas obreras. ${ }^{65}$

Finalmente las obreras lograron hacer respetar sus pedidos con la firma del pliego de condiciones que fue refrendado por el DPT. 66

El relato que a continuación emprenderemos, y que elegimos para culminar, refiere a la experiencia del soIP porque es la que más conocemos, ya que nuestro proyecto de investigación lo tiene por objeto. ${ }^{67}$

Durante los últimos días de julio y los primeros de agosto los militantes de las JJLL organizaron múltiples reuniones con obreras/os de la industria, según cuenta uno de estos militantes en sus memorias, el primer vínculo con aquellas obreras/os fue el periódico Avanzada. A través de sus páginas se llamaba a la organización del gremio para terminar definitivamente con las duras condiciones de trabajo, las largas jornadas laborales y los salarios de hambre. Luego de varias reuniones, junto a un grupo de obreras/os se organizó una Comisión Provisoria, ésta se encargó de llamar a una asamblea constitutiva del sindicato para el sábado

\footnotetext{
${ }^{64}$ La Capital, 21 de noviembre de 1942.

65 Solidaridad Obrera, diciembre 1942.

66 Véase Solidaridad Obrera, enero 1943; Ministerio de Gobierno, Condiciones de vida de la familia obrera. La regulación colectiva del trabajo, La Plata, 1943, pp.149 y 188.

67 "El enfrentamiento social como formador de territorios sociales: Los trabajadores y los empresarios de la pesca marplatense (1938-1975)", proyecto financiado por una beca tipo I de CONICET.
} 
22 de agosto, según los propios organizadores la concurrencia superó con amplitud las expectativas. Desde ese día las obreras/os del pescado tuvieron un sindicato, el soIP y el primer pliego de condiciones que los patrones debieron cumplir. Pero lograrlo no les fue fácil.

Una vez constituido el sindicato y confeccionado el pliego de condiciones, este último fue presentado a los industriales del ramo, los cuales tuvieron una semana para contestar. La respuesta patronal sería tratada en una asamblea del gremio el domingo 6 de septiembre. Llegó el día de la asamblea y los patrones no habían contestado, esa actitud determinó, por parte de la organización obrera, la declaración de la huelga general del ramo por tiempo indeterminado. En el transcurso de los 29 días que duró la huelga, ésta fue cambiando su carácter. Desde su declaración, el domingo 6 hasta el viernes 25 de septiembre la huelga tuvo carácter general en la rama, pero entre el sábado 26 de septiembre y el domingo 4 de octubre la huelga fue parcial, pues se acotó a las fábricas que no habían aceptado el pliego. Fue durante el primer momento cuando se realizó la huelga general local de solidaridad de 24 horas convocada por la UOL, que presentó elementos de huelga política de masas. También se hace necesario señalar que en el transcurso de movimiento huelguístico las obreras/os del pescado fueron creando fuerza moral y material a través de la constitución de una amplia alianza de clases, que permitió quebrar la unidad patronal y aislar al sector más concentrado y centralizado de la industria, a la vez que lograron cubrir de amplia legitimidad sus reclamos y acciones. 68

Pero, el proceso no estuvo exento de negociaciones. En los días previos a la declaración de la huelga, "las negociaciones" se llevaron acabo sin la intervención del Estado. Pero el proceso de negociación propiamente dicho comenzó el 9 de septiembre, con la huelga declarada, ya que antes de dicha medida de fuerza la patronal se negó sistemáticamente a discutir el pliego con el sindicato. Entonces, una primera reunión se realizó el miércoles o9 de septiembre en la DLDPT entre representantes del soip y de los industriales del pescado. Los primeros, que habían sido convocados al efecto de que los segundos le presentaran un contrapropuesta, se encontraron "con que los patrones manifestaron que, a parte de lo que se pudiera discutir, ellos tenían que consultar a la Unión Industrial Argentina, que es la que

68 Véase Agustín Nieto, “Anarquistas y obreras del pescado: Una experiencia de organización sindical en los años '40”, en Historia Regional n. ${ }^{\circ}$ 26, Villa Constitución, Septiembre 2008, pp.89-117. 
tiene que resolver en definitiva". ${ }^{69}$ Los representantes patronales manifestaron a la prensa local que "el Departamento del Trabajo no tiene nada que hacer con ellos; que ellos se rigen por las disposiciones y acuerdos de la Unión Industrial Argentina". ${ }^{70}$ Nuevamente, representantes del soIP y de los industriales se juntaron en la DLDPT el viernes 11 de septiembre. En esa reunión el sector patronal ofreció una contrapropuesta al pliego obrero, la misma fue rechazada por la asamblea obrera el domingo 13 de septiembre. Fue en esa reunión obrera que se consideró oportuno convocar a una huelga general para el jueves 17 de septiembre.

En un nuevo intento de llegar a un acuerdo entre las partes, el miércoles 16 de septiembre, un día antes de la huelga general, la Comisión Administrativa del SOIP junto a la UOL decidieron suspender momentáneamente la medida y llamar a una asamblea general del gremio para el jueves 17 de septiembre, ya que el día anterior ${ }^{71}$ habían recibido por intermedio de la DLDPT una nueva propuesta patronal, que consideraron en principio aceptable. En la asamblea efectuada el jueves se aceptó por unanimidad y en todos sus puntos la segunda propuesta de contrapliego presentada por los industriales por intermedio de la DLDPT, pero se acordó proseguir el paro general en la rama hasta tanto se lograra la firma de todos los industriales aceptando el pliego de condiciones del gremio, ya que faltaba la firma de "los cuatro grandes" de la pesca, Llorente, I.C.O., Pulgar y La Campagnola.

El viernes 18 de septiembre los cuatro industriales no firmantes se reunieron en La Plata ${ }^{72}$ con las autoridades del DPT e hicieron por intermedio de la mencionada repartición estatal una nueva contra propuesta a las obreras/os del pescado, lo que provocó una agudización del conflicto. Ese mismo día la UOL envió un comunicado a la prensa local donde responsabilizaba a los cuatro industriales de empujarla a tomar la decisión de convocar a una huelga general local de solidaridad para el

\footnotetext{
${ }^{69}$ El Atlántico, o9 de septiembre de 1942

${ }^{70}$ El Atlántico, 11 de septiembre de 1942

${ }^{71}$ Durante la jornada del martes 15 y bajo la presión de la declaración de huelga por parte de la UOL, el inspector general del DPT, Sr. Schenini, decidió convocar a las partes en litigio por separado, primero convocó a las obreras/os, luego a la patronal y nuevamente a las obreras/os para hacerle entrega de la contrapropuesta patronal.

${ }^{72}$ La Plata es la capital de la provincia de Buenos Aires y se encuentra a 56 kilómetros al sudeste de la ciudad de Buenos Aires.
} 
martes 22 de septiembre. Al día siguiente aparece en las páginas de El Atlántico un nuevo comunicado de la UOL en los siguientes términos:

La intransigencia de los cuatro industriales culpables de la situación planteada al pueblo de Mar del Plata -Llorente, I.C.O., Campagnola y Pulgar- provoca necesariamente esta actitud de los trabajadores porque es inconcebible que los intereses de cuatro firmas puedan más que los intereses de todos los trabajadores y comprometa la situación no solamente de éstos sino también de los industriales firmantes, y aún del mismo Departamento del Trabajo, que ha refrendado el acuerdo legado entre las partes en litigio y dicha repartición. ${ }^{73}$

El día de la huelga general, por la tarde, representantes del soIP se reunieron con el intendente municipal, Manuel González Guerrico, quien se comprometió ante las obreras/os a "interponer su gestión amistosa para lograr la más rápida solución del conflicto". ${ }^{74} \mathrm{Al}$ otro día se realizó en la Casa del Pueblo la asamblea del SOIP con la presencia del delegado local del DPT, el cual manifestó a los concurrentes que en la ciudad de La Plata se estaba realizando una reunión en el DPT con los cuatro industriales remisos. Ante esta situación la asamblea del gremio del pescado le hizo saber al delegado que el pliego ya había sido discutido y aceptado por la mayoría de los patrones, por lo cual no habría nada que discutir, e incitaron a la delegación a que hiciera uso de sus facultades para que los industriales intransigentes aceptaran y respetaran dicho pliego. Estas y otras ideas están muy bien ilustradas en el siguiente comunicado de la UOL:

... creemos, de acuerdo a las manifestaciones del señor Schenini, representante del gobierno, que no había nada que discutir, por cuanto las autoridades obligarían a que se firmase el pliego tal cual lo firmaron el resto de los industriales. (...) es necesario que el fallo no se dilate por más tiempo para evitar que los trabajadores se vean en la necesidad de recurrir a un nuevo paro general, ya que todas las demás medidas son desoídas por los cuatro industriales que parecen tener más influencias que las mismas reparticiones del Estado. ${ }^{75}$

\footnotetext{
${ }^{73}$ El Atlántico, 19 de septiembre de 1942. Cursivas nuestras.

${ }^{74}$ La Ciudad, 23 de septiembre de 1942.

${ }^{75}$ El Atlántico, 24 de septiembre de 1942. Cursivas nuestras.
} 
Durante la jornada del 24 de septiembre una delegación obrera del soIP se reunió con los pescadores en la Municipalidad, en presencia del intendente. En dicha reunión los pescadores ofrecieron al soIP el hacerse cargo de los jornales del personal de los industriales no firmantes a cambio de parcializar la huelga. La propuesta fue discutida por dos días en la asamblea del sorP y finalmente aceptada, parcializándose así la huelga el día 26 de septiembre. A partir de ese momento el proceso de negociación se intensificó y durante cuatro días consecutivos se llevaron a cabo reuniones en la ciudad de La Plata entre los cuatro remisos y las delegaciones del SOIP y la UOL intermediadas, en el DPT, por representantes de dicha repartición. El viernes 2 de septiembre se llegó a un acuerdo y una vez en Mar del Plata, el domingo 4 de octubre se realizó la asamblea del soip donde fue aprobada por unanimidad la contrapropuesta patronal. El balance realizado por la dirección anarquista del gremio fue el de un "triunfo total de los obreros de la industria del pescado". ${ }^{76}$ Pero, ¿qué fue lo que se negoció?; ¿qué diferencias hubo entre el primer convenio elevado a los industriales por el sindicato y el finalmente aceptado por ambas partes y rubricado por el DPT?; ¿̇los anarquistas imprimieron la lógica accional del "todo o nada" que se les adjudica?

El pliego de condiciones elaborado por el soIP para ser presentado ante los industriales del sector consistía, en primer término, en el pedido de reconocimiento del sindicato y las comisiones de control por "fábricas". El segundo punto establecía la duración de la jornada laboral. En tercer lugar, se decretaba la abolición del trabajo a destajo. En el ítem siguiente se hacía referencia a la escala de salarios. En el quinto punto se establecían las formas de pago. En un inciso posterior se prohibía el despido sin causa justificada. Por último, se dejaba sentado que no se podía tomar represalias contra los organizadores del gremio. Como ya señalamos, una vez presentado a los industriales, éstos en un primer momento se negaron a contestar, y luego propusieron un contrapliego que fue rechazado por el SoIP. La segunda propuesta realizada por la parte mayoritaria de la patronal fue aceptada por las obreras/os del gremio. Pero el sector más concentrado de la industria no participó de aquella propuesta y se negó a aceptarla, razón por la cual elaboró su propia oferta que fue entregada al gremio. El intento no prosperó, pues la propuesta de los "cuatro grandes" fue rechazada por el sindicato. Por último, este mismo sector empresarial realizó una segunda oferta que finalmente fue aceptada por las obreras/os

\footnotetext{
76 Véase Luis Woollands, “Triunfo Total de los Obreros de la Industria del Pescado", en El Atlántico, 5 de octubre de 1942.
} 
del gremio. Ahora veamos que puntos estaban en discusión en cada una de las propuestas.

En relación al primer ofrecimiento, el rechazo se debió a que no contemplaba ninguno de los puntos estipulados por el pliego original, y fue entendido por el gremio como una maniobra patronal y no como una verdadera contrapropuesta. La segunda oferta patronal, que implicaba algunas modificaciones para con el pliego original, fue aceptada por el gremio. En el pliego original se contemplaban 8 horas de trabajo, en el nuevo 8 horas y media una rebaja en la escala de salarios, respetando en su integridad los puntos restantes. La propuesta realizada por "los cuatro grandes" de la industria que fue rechazada por las obreras/os implicaba una rebaja aún mayor en los salarios de las mujeres y establecía que estas podían realizar cualquier tipo de trabajo, modificando así el punto del pliego original que instituía que las mujeres sólo harían trabajo de su especialidad (en particular, el descabezado y desviscerado de la anchoíta), caso contrario se les pagaría según el trabajo que realizaran. A esto se les sumaba el rechazo de los primeros tres puntos referidos al reconocimiento del sindicato y las comisiones internas, la jornada laboral de 8 horas y la abolición del trabajo a destajo. Finalmente, la propuesta aceptada por la totalidad de los industriales y la organización obrera establecía las siguientes modificaciones: jornada de 9 horas diarias y 48 horas semanales, salario de \$4 para las mujeres (sólo trabajo de su especialidad y en remachadoras automáticas). Aceptando en su totalidad los puntos restantes.

De lo expuesto se evidencia que uno de los puntos más resistidos por el conjunto de los industriales fue el referido a los salarios y función de las mujeres debido a que éstas representaban el 90\% del personal. Por otro lado, notamos que "los cuatro grandes" resistían tenazmente no sólo el punto mencionado, sino también y quizás más vehementemente, los referidos a la organización sindical, a la duración de la jornada laboral y al trabajo a destajo. El primero vinculado a la función de garante del cumplimiento del pliego por parte de las obreras/os, el segundo y el tercero relacionados con la tasa de explotación y plusvalía absoluta y relativa extraída a las obreras/os que implicaban una gran cuota de ganancia principalmente al sector más concentrado de la industria. También pudimos ver un desarrollo desigual en la rama que se tradujo en el problema de la función cumplida por las obreras en el proceso de producción y su tratamiento en la discusión sobre el pliego de condiciones. Este desarrollo desigual se evidencio en el ítem de las funciones de las obreras referidas a las remachadoras automáticas y las no automáticas. Vol- 
viendo a la problemática del salario para el conjunto de las categorías, podemos ver cuál fue el porcentaje promedio de aumento en la rama. Este primer cálculo lo realizamos haciendo abstracción de las condiciones de trabajo en la situación previa, entiéndase por esto el trabajo a destajo, las jornadas de entre 12 y 16 horas, y referidas a los salarios máximos. De esta forma, la estimación establece el precio de la fuerza de trabajo por jornada sin considerar el modo en que era utilizada. Así considerado, el aumento pedido con el pliego original representaba un $73,7 \%$, mientras que el finalmente obtenido fue de $63,2 \%$. Si ahora consideramos el precio de la fuerza de trabajo por hora las estimaciones cambian, mientras que en las condiciones previas el salario por hora era de $\$ 0,32$ en el pliego original ascendía a $\$ 0,83$, lo que hubiera representado un aumento del $159,4 \%$, pero el aceptado por los industriales lo establecía en $\$ 0,69$, lo que representó un 115,6\% de aumento. ${ }^{77}$

Resumiendo lo expuesto en este apartado, evidenciamos que la dirección anarquista no sólo negoció varios puntos con la patronal, sino que tuvo la necesidad de ceder en varios de ellos para lograr la definitiva organización del gremio. Los ítems negociados fueron los salarios, la duración de la jornada de trabajo y las tareas realizadas por las mujeres.

\section{Palabras finales}

A lo largo del trabajo nos propusimos ilustrar algunos rasgos del $\mathrm{SCH}$ y ponerlos en discusión con prácticas anarquistas que se sitúan por fuera de aquellas fronteras. La existencia de anarquistas en los años cuarenta no respondió a la persistencia testaruda pero decadente de los despojos foristas, nuestros anarquistas no fueron viejos militantes de la FORA impermeables a los cambios sociales que se producían en el país. Tampoco fueron renegados que pasaron al sindicalismo o al comunismo. Aquellos hombres y mujeres fueron parte constituyente y constitutiva de una nueva generación de anarquistas que con una gran sensibilidad de izquierda, y rebelándose contra "el ya no", supieron acompañar las transformaciones en el mundo obrero

77 Otro cálculo importante en este punto sería el referido a la relación salario/productividad, pero debido a la falta de fuentes que contengan la información necesaria se nos hace imposible realizarlo. 
y, a la vez que enseñaron, aprendieron de la lucha, organización y negociación de la clase obrera. ${ }^{78}$

Esta nueva generación de anarquistas, al igual que otras tendencias político ideológicas de izquierda, ayudaron a construir, militaron y dirigieron sindicatos de industria, hicieron uso de las leyes obreras, no se opusieron irreductiblemente a la institucionalización del movimiento obrero y, ante las mutaciones del aparato estatal, aceptaron, gustosos mucha veces, la mediación del Estado en los procesos de negociación obrero-patronales. ¿Estas prácticas nos tienen que hacer dudar de su caracterización como anarquistas o nos tiene que hacer dudar de los postulados del SCH construido sobre el anarquismo? ¿Será que las corrientes político-sindicales, como la anarquista, pueden elegir libremente los repertorios organizacionales y de lucha o será que estas elecciones están condicionadas por el contexto sociohistórico? Lejos de querer presentar estas prácticas como dominantes "en el anarquismo argentino", lo que pretendemos mostrar es que existieron y que esta existencia es disruptiva para con las "verdades" del sch. No es que "el árbol tape al bosque", por lo contrario consideramos que ningún relato sobre "el anarquismo argentino" se basa en una visión total del bosque. Pues cada uno de nosotros no tiene frente de si más que un árbol, el cual nos permite imaginar el bosque, en nuestro caso uno muy heterogéneo.

Llegados a este punto sería conveniente aclarar que nuestra estrategia expositiva no se condice con nuestra estrategia de investigación. Esta última tiene como puerta de entrada a la realidad social el conflicto, la lucha, el enfrentamiento, ya que lo consideramos estructurante de lo social. Sin embargo, el "descubrimiento", en nuestra investigación sobre la historia del soIP, de la presencia anarquista en la dirección de este sindicato durante los períodos 1942-1948 y 1955-1966 y las características poco "ortodoxas" de sus prácticas, nos motivo a profundizar en esta línea. Por eso decidimos exponer no la trayectoria de los conflictos obreros sino la de una de sus resultantes: los anarquistas negociadores.

\footnotetext{
78 Para trabajos que se sitúan en una perspectiva similar a la nuestra, aunque no asimilable, véase Nicolás Iñigo Carrera, "La Alianza Obrera Spartacus", en PIMSA 2000, Buenos Aires, 2000, pp.97171; Javier Benyo, La Alianza Obrera Spartacus. Anarquismo, vanguardia obrera e institucionalización del movimiento sindical en la década de 1930, Buenos Aires, Libros de Anarres, 2005; Fernando López Trujillo, Vidas en rojo y negro. Una historia del anarquismo en la "Década Infame", La Plata, Letra Libre, 2005.
} 
Por último, nos gustaría terminar con una conjetura sobre el virtual ocaso los anarquistas. Como existe un consenso para determinar "el ya no" de "el anarquismo" en el año 1930, existe otro que establece la interrupción de la fructífera experiencia socialista y comunista en el mundo obrero con la irrupción del peronismo. A sabiendas de que la interrupción no fue total y que las izquierdas siguieron presentes en el mundo de los trabajadores, es también fácilmente perceptible que esa presencia se vio menguada por la experiencia peronista. Ahora bien, consideramos que, al igual que socialistas y comunistas, los anarquistas estaban desarrollando fructíferas experiencia en el mundo del trabajo durante las décadas del 30 y 40, pero, también al igual que socialistas y comunistas, vieron parcialmente eclipsadas sus trayectorias por la sustanciación del peronismo. Sin embargo, esta ruptura en la esfera de las tendencias político-ideológicas se conjugaba con la continuidad y afianzamiento de una estrategia reformista en el seno de la clase obrera argentina.

\section{Bibliografía:}

\section{Fuentes primarias:}

El Atlántico

La Capital

Solidaridad Obrera

FACA, Resoluciones del Segundo Congreso Ordinario, Buenos Aires, 7, 8 y 9 de julio de 1940.

Ministerio de Gobierno, Anuario estadístico 1943, La Plata, 1944.

Ministerio de Gobierno, Condiciones de vida de la familia obrera. La regulación colectiva del trabajo, La Plata, 1943.

\section{Fuentes secundarias:}

Abad de Santillán, Diego, La FORA. Ideología y trayectoria del movimiento obrero revolucionario en la Argentina, Buenos Aires, Libros de Anarres, 2005.

Acha, Omar y Quiroga, Nicolás, "Pliegues de la normalización de los estudios sobre el primer peronismo: complementos y aclaraciones", en Raanan Rein, Carolina Barry, Omar Acha y Nicolás Quiroga, Los estudios sobre el primer peronismo. Aproximaciones desde el siglo XXI, La Plata, 2009, pp.81-102. 
Barrancos, Dora, Anarquismo, educación y costumbres en la Argentina de principios de siglo, Buenos Aires, Contrapuntos, 1990.

Bayer, Osvaldo, Severino Di Giovanni, el idealista de la violencia, Buenos Aires, Galerna, 1970.

Bayer, Osvaldo, La Patagonia rebelde, 2 tomos, Buenos Aires, Página/12, 2009.

Benyo, Javier, La Alianza Obrera Spartacus. Anarquismo, vanguardia obrera e institucionalización del movimiento sindical en la década de 1930, Buenos Aires, Libros de Anarres, 2005.

Edgardo, Bilsky, La FORA y el movimiento obrero, 2 tomos, Buenos Aires, CEAL, 1985.

Campo, Hugo del, Los Anarquistas, Buenos Aires, CEAL, 1971.

Chakrabarty, Dipesh, Al margen de Europa. ¿Estamos ante el final del predominio cultural europeo?, Barcelona, Tusquets, 2008.

Cordone, Héctor, "Reflexiones sobre movilizaciones populares y movimiento obrero argentino durante el primer peronismo (1946-1955)", en Sociología del Trabajo n. ${ }^{\circ} 6$, Buenos Aires, Piette, 2000.

Carrera, Nicolás Iñigo, "La Alianza Obrera Spartacus”, en PIMSA 200o, Buenos Aires, 2000, pp.97-171.

Godio, Julio, La Semana Trágica de enero de 1919, Buenos Aires, Hyspamérica, 1985.

Godio, Julio, El movimiento obrero argentino (1870-1910). Socialismo, anarquismo y sindicalismo, Buenos Aires, Legasa, 1987.

López Trujillo, Fernando, Vidas en rojo y negro. Una historia del anarquismo en la "Década Infame”, La Plata, Letra Libre, 2005.

Nieto, Agustín, “Anarquistas y obreras del pescado: Una experiencia de organización sindical en los años '40", en Historia Regional n. ${ }^{\circ} 26$, Villa Constitución, Septiembre 2008, pp.89-117.

Oved, Iaacov, El anarquismo y el movimiento obrero en Argentina, México, Siglo XXI, 1978.

Oved, Iaacov, "El trasfondo histórico de de la Ley 4.144 de Residencia", en Desarrollo Económico vol.6, n. ${ }^{\circ} 61$, Buenos Aires, 1976, pp.123-150. 
Oved, Iaacov, "Influencia del anarquismo español sobre la formación del anarquismo argentino", en EIAL, [online], vol.2, n. ${ }^{\circ}$, enero-junio 1991, http://www.tau.ac.il/eial/II_1/oved.htm. [citado 27 Julio 2009].

Oved, Iaacov, "The Uniqueness of Anarchism in Argentina", en EIAL, [online], vol.8, n. ${ }^{\circ}$, enero-junio 1997, http://www.tau.ac.il/eial/VIII_1/oved.htm. [citado 27 Julio 2009].

Suriano, Juan, Movimientos sociales: la huelga de inquilinos de 1907, Buenos Aires, CEAL, 1983.

Suriano, Juan, Trabajadores, anarquismo y Estado represor: de la Ley de Residencia a la de Defensa Social (1902-1910), Buenos Aires, CEAL, 1988.

Suriano, Juan, “Ideas y prácticas políticas del anarquismo argentino”, en Entrepasados n. ${ }^{\circ}$, Buenos Aires, 1995, pp.21-48.

Suriano, Juan, "Las prácticas políticas del anarquismo argentino", en Revista de Indias vol.LVII, n. ${ }^{\circ}$ 210, Madrid, CSIC, 1997, pp. 421-450.

Suriano, Juan, "El anarquismo”, en Mirta Z. Lobato (dir.), El progreso, la modernización y sus límites, 1880-1916, Buenos Aires, Sudamericana, 2000, pp.291-325.

Suriano, Juan, "La oposición anarquista a la intervención estatal en las relaciones laborales", en Juan Suriano (comp.), La cuestión social en Argentina 1870-1943, Buenos Aires, La Colmena, 2000, pp.89-110.

Suriano, Juan, Anarquistas. Cultura y política libertaria en Buenos Aires, 189o-1910, Buenos Aires, Manantial, 2001.

Suriano, Juan, Auge y caída del Anarquismo. Argentina, 1880-1930, Buenos Aires, Capital Intelectual, 2005.

Tarcus, Horacio (director), Diccionario biográfico de la izquierda argentina. De los anarquistas a la "nueva izquierda" (1870-1976), Buenos Aires, Emecé, 2007, pp.1-3.

Zaragoza Ruvira, Gonzalo, Anarquismo Argentino, Madrid, Eds. de la Torre, 1996. 